\title{
Domestic Cells, State of health Tester, Charger (Open Source)
}

\author{
A. SIVERT ${ }^{1}$, S. CARRIERE ${ }^{1}$, F. BETIN ${ }^{1}$, PH. DONDON ${ }^{2}$ \\ (1) I.U.T de l'Aisne Département Génie Electrique SOISSONS FRANCE \\ Laboratory for Innovative Technologies (L.T.I), Team Energy Electric and Associated System \\ (2) Université de Bordeaux, IPB Av Dr A. Schweitzer 33405 Talence FRANCE
}

\begin{abstract}
In France, the annual average purchases per person is 19 primary household batteries and 2 rechargeable batteries. Despite the obligation for each battery seller to have a collection point, only $50 \%$ of these domestic accumulators are recycled in France.

Among the numerous reasons that users do not use home rechargeable NiMH batteries to their discharge limits, this article will mainly discuss the lack of easy-to-use and inexpensive function testing. An "open source" testerloader with many possibilities is proposed. In particular, a test by the linear regression method making it possible to reduce the test duration of NiMH batteries from 6 hours to 1.5 hours to check the energy capacity of each accumulator is presented. Since 2019, lithium-ion batteries in domestic cases have been marketed with few characteristics provided by manufacturers on their obsolescence and their capacities. In this article we present performance tests carried out to verify the energy capacity as a function of the output current.
\end{abstract}

Key-Words: Domestic Battery, NiMH, open source, Arduino, charger, tester, $\mathrm{SOH}$ (state of health).

Received: February 2, 2021. Revised: August 13, 2021. Accepted: August 21, 2021. Published: September 2, 2021.

\section{Introduction}

In 2018 in France, 1,405 million portable batteries and accumulators were marketed for a total of 31,246 tons, or 21 batteries and accumulators per inhabitant and per year.

In number of units, alkaline batteries represent $60 \%$ and button cells $25 \%$ of the total. Note that alkaline batteries require 50 times more energy to manufacture than they can provide during their lifetime [1]. In addition, the recycling of accumulators is only $50 \%$ in France despite collection points and recycling communication [2].

The environmental performance of domestic primary batteries [3] is therefore very poor. NiMH rechargeable batteries, marketed since 1990, should have been replaced these alkaline batteries which cost 400 times more expensive compared to its rechargeable counterpart.

The increase in the use of rechargeable lithium-ion batteries is mainly done in systems requiring high currents $(>1 \mathrm{~A})$, portable power systems and connected objects whose use has grown in recent years.

The statistics of the world market for accumulators are given in figure 1 [4]. We see that the consumption ratio between the different types of battery is comparable to those of the French market and that the turnover of primary batteries is low compared to secondary batteries because they are small units in energy capacity.
Why have secondary batteries not replaced primary batteries at home?

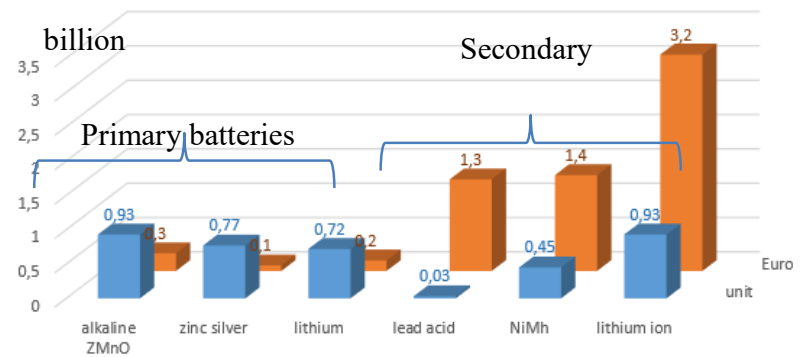

Fig 1. Worldwide market for accumulators 2018.

The factors of non-replacement of primary batteries are numerous despite the promotion of many major public magazines demonstrating the significant savings made with NiMH cells $[5,6]$. Among these we can cite:

- The energy capacity of NiMH decreases by approximately $15 \%$ during the first 24 hours (selfdischarge) and $15 \%$ more every month. So, they are often half empty when you want to use them.

- The failure of a single element in series is enough for the system to stop working.

- Portable power systems rarely give the state of charge with good accuracy and battery health.

- The chargers do not give the state of charge and do not test the batteries and are very slow (10 hours of charging, while an hour of charging under certain conditions is possible).

- Before the battery is totally faulty, it may have the right voltages but an internal resistance that is three times the nominal value as well as an energy capacity 
divided by two, reducing the normal operating time as much.

- You usually need several chargers depending on the cases of batteries.

- Users lack sufficient electricity culture to test a battery.

Why aren't manufacturers using more lithium ion batteries in systems?

The cases of household batteries are different from those used for the predominant NiMH cells in this use.

However, the advantages of $\mathrm{Li}$ are numerous:

- the price of a Li 18650 cell is roughly the same as that of a NiMH AA cell.

- Lithium elements have about 4 times more energy for the same number of cycles (500 to 1000).

However, since the voltages are not the same between lithium and NiMH accumulators, voltage regulators must be used.

Why is it difficult to replace a lithium battery in a system?

Manufacturers spot-weld their batteries together or often use JST connectors so that the connection is flawless and thus avoid hot spots and energy losses when used with high currents.

Since 2019, it is possible to find in domestic AA, AAA, PP3 battery boxes lithium "pocket" elements with USB charger, as can be seen in figure 2 .

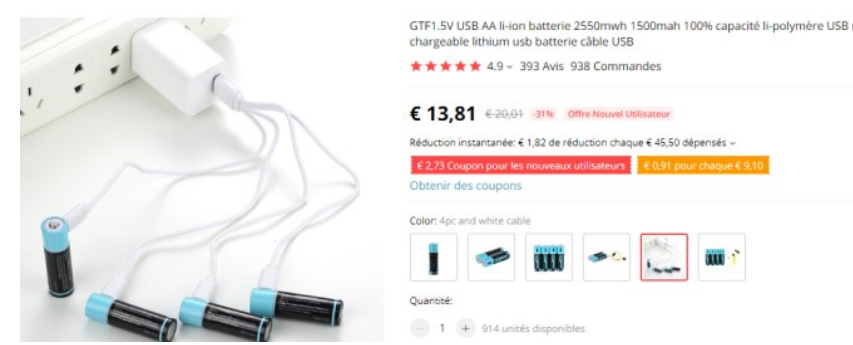

Fig 2. Lithium battery USB box AA.

These batteries cost the same as a NiMH cell and their charge and discharge currents are linked to the possibilities of electronics. However, these batteries remain difficult to find in supermarkets, for general public uses. Will this technology be better tamed by consumers? Will this technology make NiMH cells obsolete and minimize primary battery consumption? These questions imply others of a more technical nature to which we propose to answer in this article. In the next paragraph, we first look at the essential characteristics of NiMH batteries.

For our technical study, more than 10 batteries from different supplier were experimented in order to obtain significant results.
This article will recall the characteristics of domestic NiMH batteries. Then what are the methods to test them simply by linear regression? How to load them quickly and at what value? This article presents a low cost tester and charger with a small processor. In addition, a cycler can be carried out to verify Aging and test NiMH and to perform consumer tests.

\section{NiMH characteristics}

Datasheets often give the voltage as a function of time and sometimes as a function of the consumed energy capacity for different current values as can be seen in Figure 3:

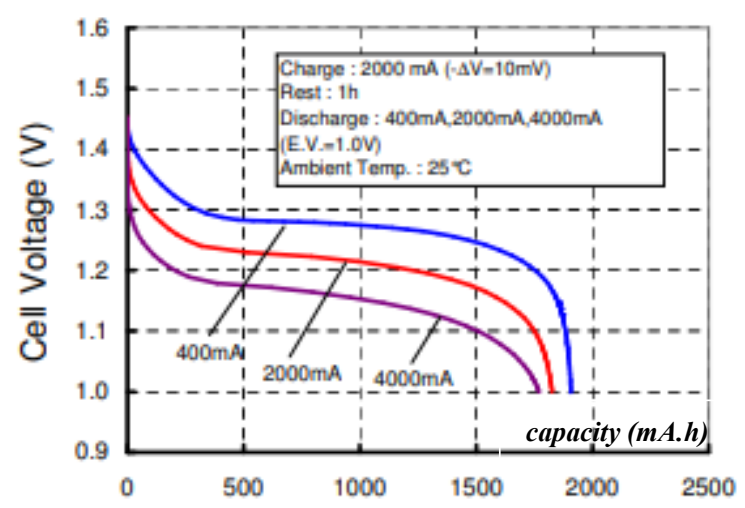

Fig 3. NiMH typical voltage according to the consumed capacity for AA case [7]

Despite the international standard CEI 61951-2, manufacturers rarely give the resistance ESR causing the voltage sag but rather the impedance at $1 \mathrm{kHz}$. However, there is an important difference between these 2 values [8].

Indeed, the electrochemical element can be simply modeled by the following electric model [9] (with $\mathrm{OCV}=($ open circuit voltage):

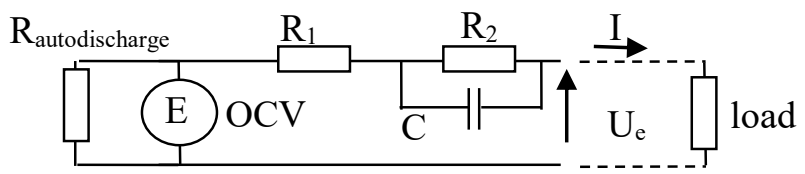

Fig 4. Electrical model of a battery cell

During a discharge current pulse $\mathrm{I}$, the cell voltage $\mathrm{U}_{\mathrm{e}}$ will correspond to the following equation with a voltage drop corresponding to $(\mathrm{R} 1+\mathrm{R} 2)=\mathrm{ESR}$ :

$U_{e}(t)=E-\left(R_{1}+R_{2}\right) \cdot I+R_{2} \cdot I \cdot e^{\frac{-t}{R_{2} \cdot C}}$

The impedance is given by the following equation $Z(f)=\left(R_{1}+R_{2}\right) \cdot \frac{\left\lfloor 1+i \cdot f / f_{2}\right\rfloor}{\left[1+i \cdot f / f_{1}\right]}$

with: 


$$
\mathrm{f}_{2}=\frac{1}{\left(\mathrm{R}_{1} / / \mathrm{R}_{2}\right) \cdot \mathrm{C} \cdot 2 \cdot \pi} \text { and } \mathrm{f}_{1}=\frac{1}{\mathrm{R}_{2} \cdot \mathrm{C} \cdot 2 \cdot \pi}
$$

So, the impedance at $1 \mathrm{kHz}$ gives the resistance $\mathrm{R} 1$ as can be seen in the figure 5 .

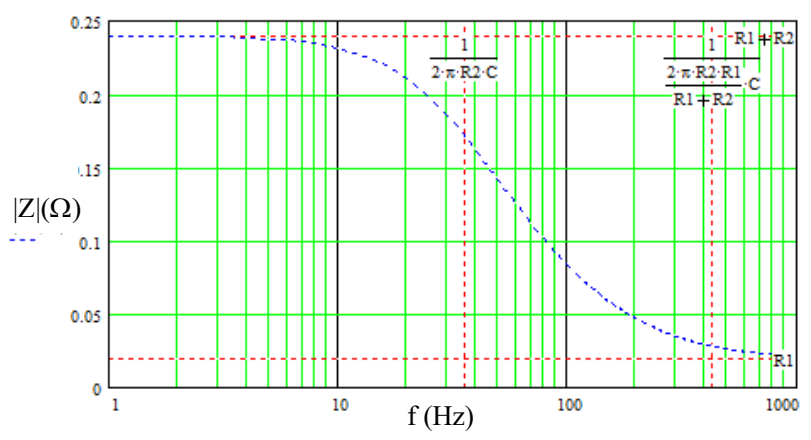

Fig 5. Impedance AA NiMH element vs frequency.

The manufacturers do not provide the data necessary to be inserted into a Matlab model making it possible to determine the battery operating time for a system [10].

For a PP3 element, the ESR is around $45 \Omega$ while the impedance module is $0.63 \Omega$ [11].

Typical values are reported in Table 1 according to the case with their maximum discharge currents.

Table 1: characteristics of different case NiMH home battery contacts (with contact resistance $0.1 \Omega)$

\begin{tabular}{|l|l|l|l|l|}
\hline case & $\mathrm{V}$ & $\mathrm{mA} . \mathrm{h}$ & $\mathrm{ESR}(\Omega)$ & rate $_{\max }$ \\
\hline AA & 1.2 & 2200 & 0.25 & $1 \mathrm{~A}$ \\
\hline AAA & 1.2 & 800 & 0.35 & $0.5 \mathrm{~A}$ \\
\hline PP3 & 8.4 & 200 & 45 to 4 & $0.05 \mathrm{~A}$ \\
\hline
\end{tabular}

ESR given in table 1 includes internal serial resistance and contact resistance. But electrolytic leaks and oxidation of the contacts may multiply this value by ten, causing possible improper operation.

If the characteristics of major brands of batteries are accessible, their prices are 3 times more expensive than generic batteries. On the other hand, the characteristics of generic batteries are rarely accessible. However, this would make it possible to prove that these generic elements do indeed have the indicated characteristics of their packaging taken over by the sellers.

Only a few independent consumer blogs provide test characteristics and verify data for different brands and sub brands $[12,13]$.

What are the energy capacities of a battery according to its internal resistance?

When the internal resistance of the battery is not negligible, the energy capacity Q will depend on the discharge current due to the voltage drop caused by this resistance. Limiting the discharge current therefore requires a choice of battery and a number of cells to be placed in series or parallel depending on the desired load.

\section{NiMH cell mounting configuration}

The notation for parallel series cell configurations is $\mathrm{xSxP}$. But in domestic, it is rare to put parallel elements as for lithium cells.

It is the SOH (State of health) of the weakest element in series that is decisive. So, it only takes one failed part for the system to stop working.

Depending on the desired output current, the choice of the packaging must then be made according to the consumed energy capacity and the number of elements in series to be used knowing that the voltage and the ESR resistance of the complete battery increases when the number of cells in series increases. Hereafter, we present two examples for type AA and PP3 cases.

\subsection{Characteristics NiMH PP3 200mA.h}

The study of this case makes it possible to observe the problem of NiMH elements. The PP3 case has 7 series NiMH cells with a nominal voltage $V_{n}$ of $8.4 \mathrm{~V}$ and allows easy observation of the change in internal resistance as a function of discharge and charge.

In Figure 6, we observe the evolution of the discharge voltage as a function of time (horizontal scale represents $1 / 2 \mathrm{~h}$ ) for a given discharge current at $45 \mathrm{~mA} \pm 5 \mathrm{~mA}$ (i.e. discharge rate $\approx \mathrm{C} / 4$ ). Because of the high internal resistance of the accumulator, the battery voltage (blue curve) is much lower than the nominal voltage $V_{n}$ and the consumed energy capacity (green curve) is much lower than that given by the manufacturer (cf. Fig 8). Stair shape of capacity results of the integration of current (numerical calculation). We can observe a few discharge stops to measure the OCV and ESR.

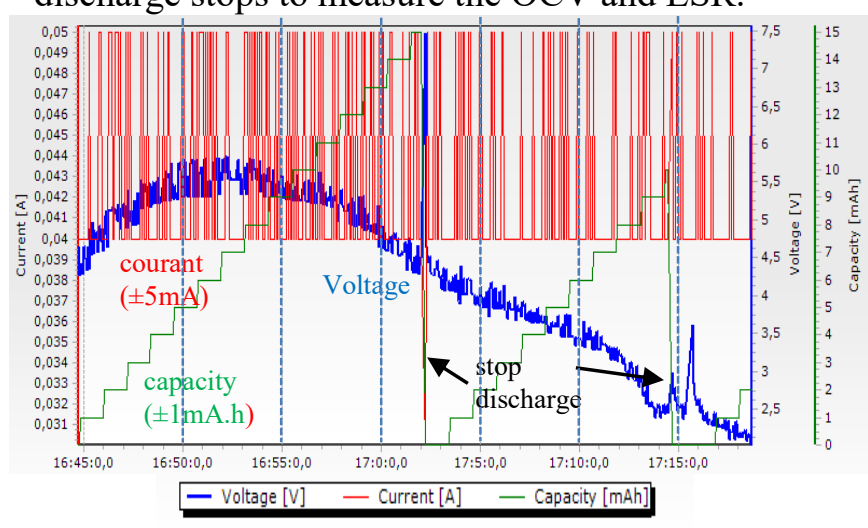

Fig 6. Evolution of the voltage of a NiMH PP3 battery (discharge current of $0.045 \mathrm{~A}$ ) at $25^{\circ} \mathrm{C}$ 
In Fig. 7, we observe this voltage (blue curve) as a function of the consumed energy capacity, as well as the variation of the resistance (orange curve: ESR comprised between 30 and $100 \Omega$ ).

The ESR resistance increases when the battery is heavily charged and at the end of charging.

Since the internal resistance is relatively large, the energy capacity lost is obviously not negligible.

This Ah capacity lost in the resistor is determined by the following equation and can also be seen in Figure 7 (grey curve).

$$
Q_{\text {lost }}(m A h)=\frac{O C V-U b}{O C V} \cdot I \cdot \frac{\operatorname{time}(s)}{3,6}=\frac{E S R \cdot I^{2}}{O C V} \frac{\operatorname{time}(s)}{3,6}
$$

The linear regression $[14,16]$ of the voltage as a function of the energy capacity Q (blue dotted line on fig. 7) is given by the following equation with the 2 unknowns $a$ and $b$.

$$
U_{\text {batterie }}=a \cdot Q+b-E S R \cdot I
$$

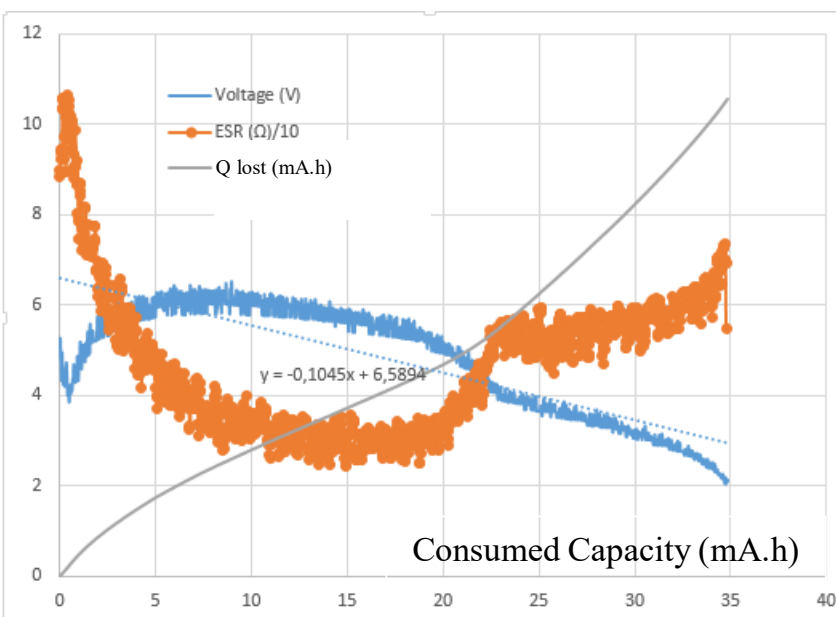

Fig 7. Evolution of the battery voltage, resistance and lost capacity of a NiMH PP3 battery (discharge current of $0.045 \mathrm{~A}$ ) at $25^{\circ} \mathrm{C}$.

Without taking into account the lost capacity, for a certain desired discharge current value and a given discharge stop, the energy capacity of the battery will decrease corresponding to the following equation:

$Q(m A h) \approx \frac{\left(U_{\text {stopdischarge }}+E S R \cdot I\right)-b}{a}$

Example: For a discharge arbitrary stop voltage of $2 \mathrm{~V}$, the energy capacity for the PP3 is shown in Figure 8.

A discharge rate lower than $\mathrm{C} / 20$ must be used to find a capacity close to that given by the manufacturer but this requires a time of more than 20 hours for a $100 \%$ discharge allowing the battery to be tested and its condition to be checked state health.

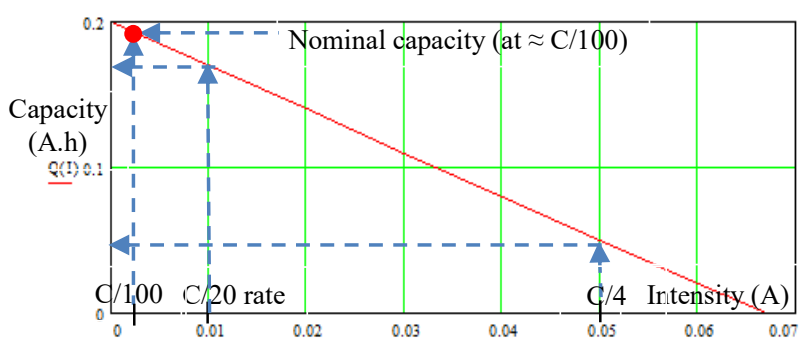

Fig 8 . NiMH real energy capacity according to the discharge current of a NiMH battery pack PP3 at $25^{\circ} \mathrm{C}$

\subsection{NIMH AA 2300mA.h characteristics}

The discharge current of a type AA case of a NiMH cell allows a discharge current of $1 \mathrm{~A}$ to be obtained. We can observe the variation of the energy capacity, following the ESR of $0.25 \Omega$ for a battery voltage discharge stop of $1 \mathrm{~V}$.

Note: Since the resistance changes with temperature, this capacity also varies with temperature.

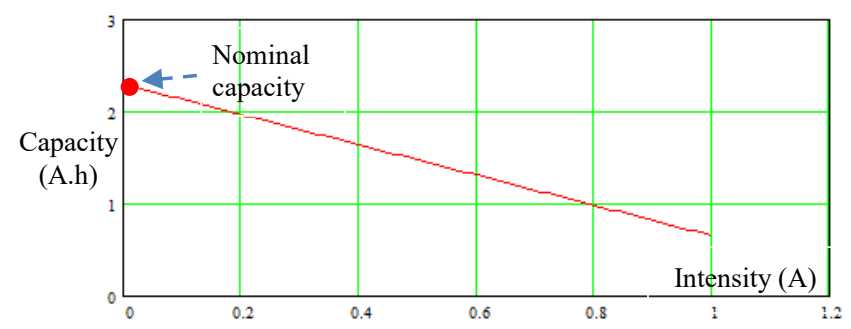

Fig 9. Energy capacity depending on the discharge current of an AA NiMH battery pack at $25^{\circ} \mathrm{C}$

The figure 10 shows the battery voltage as a function of the consumed energy capacity for a discharge current of $0.5 \mathrm{~A}$.

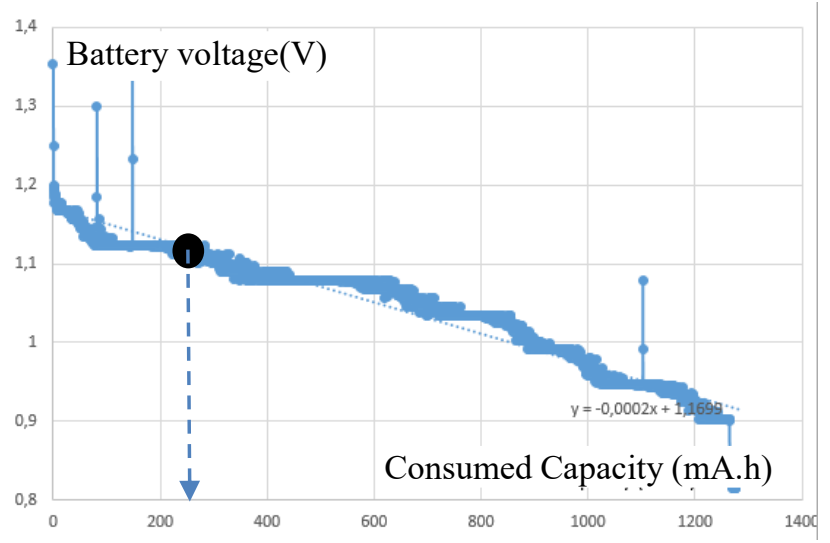

Fig 10 . NiMH type AA battery voltage at $25^{\circ} \mathrm{C}$ with discharge stop at $0.8 \mathrm{~V}$ for a discharge current of $0.5 \mathrm{~A}$ which gives a use of $1.3 \mathrm{~A} . \mathrm{h}$.

The voltage drop as a function of the energy capacity can be observed as well as the trend curve (dotted line) of the voltage as a function of the consumed capacity. The black point (intersection between these 
2 curves) gives the "threshold" value of the energy capacity to be used (here, 230mA.h) to estimate the total available energy capacity, avoiding a full $100 \%$ battery discharge.

Moreover, the coefficient ' $a$ ' of the linear regression [16] do not change significantly when the consumed capacity becomes greater than $230 \mathrm{~mA} . \mathrm{h}$, as can be seen in the figure 11 .

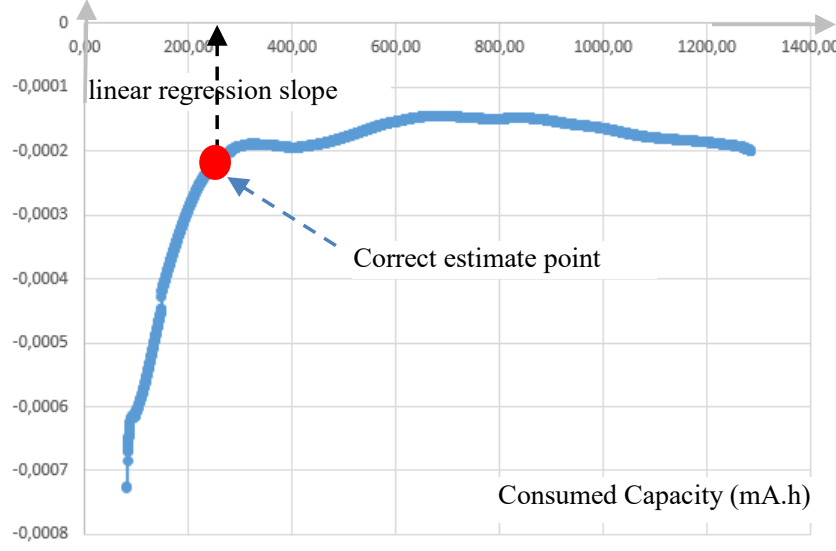

Fig 11. Evolution of the coefficient "a" of equation (5) of the estimation by linear regression

Lastly, figure 12 shows the State of health ( $\mathrm{SOH})$ as function of consumed capacity.

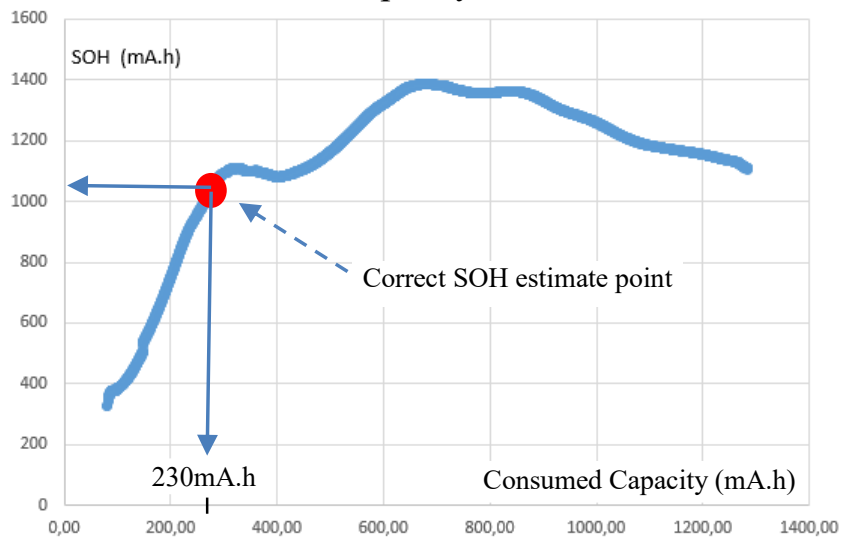

Fig 12. Estimation of $\mathrm{SOH}, \mathrm{NiMH}$ AA battery $2300 \mathrm{~mA}$.h with $0.5 \mathrm{~A}$ discharging current

Since SOH and ' $\mathrm{a}$ ' coefficient do not hardly change, when the consumed capacity is greater than the "threshold" value 230mA.h, (red point), we can state that it is no more necessary to perform a long $100 \%$ discharge of the NiMH elements, to get the $\mathrm{SOH}$ value: Thus, using this $\mathrm{SOH}$ estimate strategy, it becomes possible for users to check (or estimate) the energy capacity in a relatively reduced time.

Here, the necessary discharge time (at $0.5 \mathrm{~A}$ ) to obtain a good estimate of $\mathrm{SOH}$ will therefore be about $0.5 \mathrm{~h}$.
The question could be: Does increasing discharge current allow for faster health assessment?

So, we did a second test reported in figure 13 with the following conditions: Discharging current $1 \mathrm{~A}$, and stop at $0.5 \mathrm{~V}$ (because of the voltage drop caused by this large current). It is observed that the slope "a" is practically identical. However, the coefficient "b" has greatly decreased.

For this value of the current, the good estimate of the $\mathrm{SOH}$ with the linear regression and an consumed energy capacity of $600 \mathrm{~mA} . \mathrm{h}$, requires a duration of 36 minutes.

So, the estimation time is almost the same.

Note: Since the discharge is stopped at a lower voltage than before, the consumed energy capacity is close to the nominal capacity (2300mA.h).

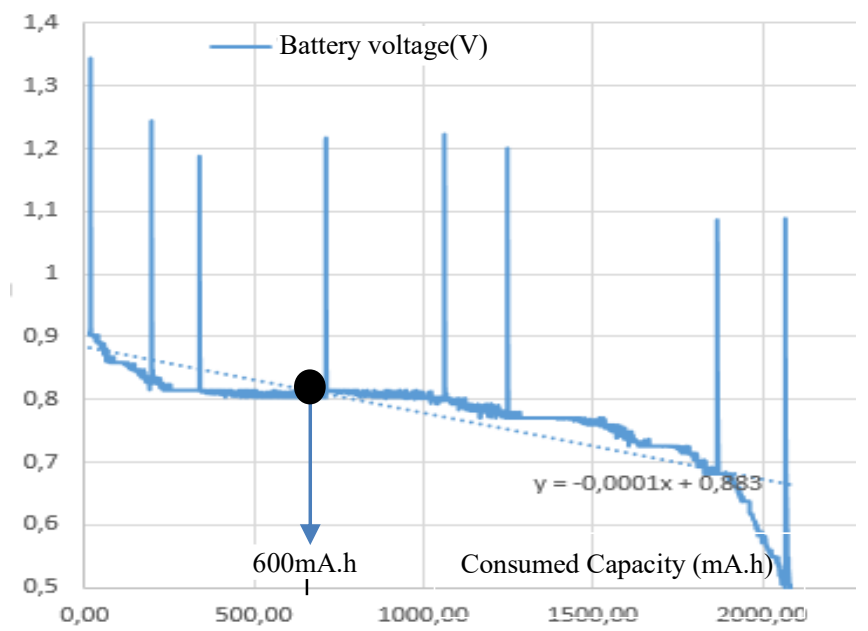

Fig 13. NiMH type AA battery voltage at $25^{\circ} \mathrm{C}$ with discharge stop at $0.5 \mathrm{~V}$ for a current of $1 \mathrm{~A}$

\section{NiMH cell charge}

To test NiMH batteries, make sure the battery is $100 \%$ charged.

Several charging methods exist:

- Infinite charge with constant currents lower than $\mathrm{C} / 20$. But the charging time is over 20 hours.

- Charge in 2 hours maximum with detection of the negative slope of the battery voltage as a function of the $\mathrm{dv} / \mathrm{dt}$ time. The accuracy of the battery voltage measurement must be important because if it is not detected, the energy that is no longer transformed into chemistry is transformed into heat and risks degrading the element.

- Charge in one hour maximum with detection of the increase in temperature of the NiMH element.

time $_{\text {estimate }}=\mathrm{Q}_{\text {estimate }}(\mathrm{A} . \mathrm{h}) / \mathrm{I}(\mathrm{A})=0.23 / 0.5 \cong 0.5 \mathrm{~h}$ 
In figure 14, [17] we can observe the detection of the temperature divergence at the end of charging thanks to a $10 \mathrm{k} \Omega$ NTC (Negative Temperature Coefficient).

On commercial chargers, the To220 case temperature sensors with an LM35 are not used much while it is easy to connect it to the + terminal (without spring) of the accumulator. There are also inexpensive contactless infrared temperature sensors such as the MLX90614.

\section{A NiMH Charge Cycle at 1C}

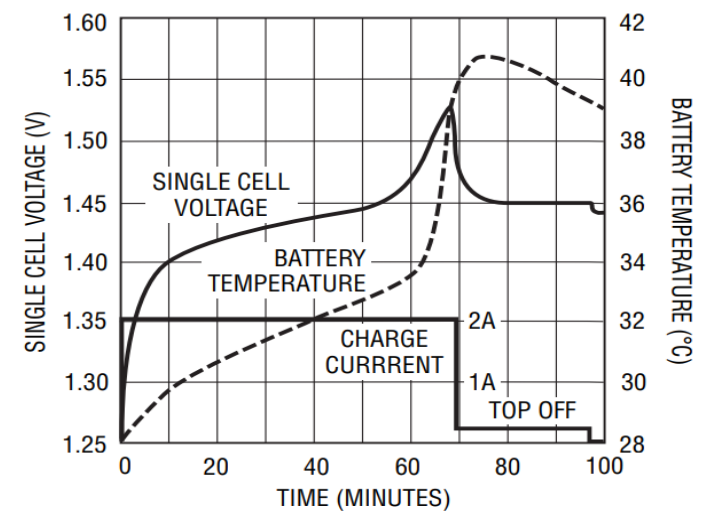

Fig 14. NiMH type AA Battery charge controller by the LTC4010

In Figure 15, we can see the constant current charge of a PP3 element. (Horizontal scale represents $\approx 50$ minutes) There is an initial important over voltage (blue curve) because of the internal resistance of the cell at the beginning of charging. Then, charging is stopped when the measured temperature (light blue curve) reaches $38^{\circ} \mathrm{C}$ according to fig 14 . Green curve represents the evolution of capacity (mA.h) during the charging process.

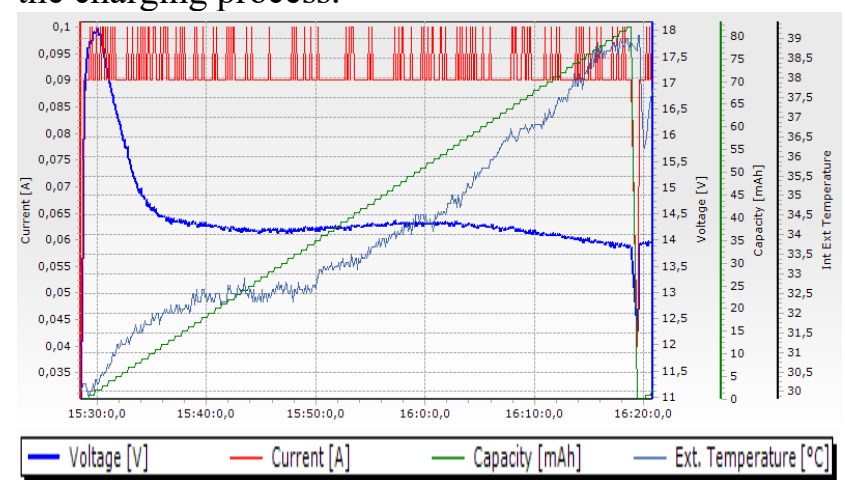

Fig 15. NiMH battery voltage PP3 case at $25^{\circ} \mathrm{C}$ ambient charging at $0.1 \mathrm{~A}$

The charging voltage for a AA type 2.3A.h (blue curve in V) and temperature (orange curve in ${ }^{\circ} \mathrm{C} / 20$ ) as a function of the energy capacity are shown in figure 16.

Knowing the internal resistance, it is possible to estimate, through linear regression, the time required to reach $100 \%$ load.
On some blogs, home battery chargers and testers are tested, but to date, only model-making chargers can properly test NiMH batteries by delivering time curves via USB.

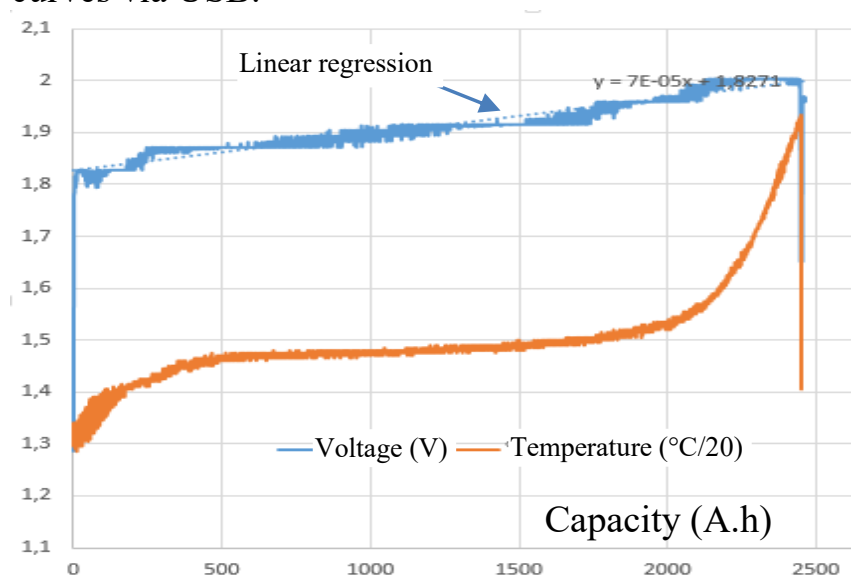

Fig 16. NiMH battery voltage type AA 2.3A.h at $25^{\circ} \mathrm{C}$ ambient charging at constant $1 \mathrm{~A}$ at $0.5 \mathrm{C}$.

However, they do not give the SOH health status of the elements.

Even if a basic knowledge of batteries is enough to analyse these curves and to know if the element is still correct or faulty, this remains difficult for the "average" user.

To meet this need, an "open source" battery charger to estimate this state of health $(\mathrm{SOH})$ has been designed.

\section{NiMH low cost Battery Tester and Charger with Arduino}

To minimize test time, we have adopted the following intensity values for the specifications of the tester intended for different types of case:

\begin{tabular}{|l|l|l|l|}
\hline case & $\mathrm{I}_{\text {charge }}$ & $\mathrm{I}$ discharge & $\mathrm{V}_{\text {stop }}$ \\
\hline AA & $1 \mathrm{~A}$ & $1 \mathrm{~A}$ or $0.5 \mathrm{~A}$ & $0.5 \mathrm{~V}$ \\
\hline AAA & 0.5 & 0.5 or $0.25 \mathrm{~A}$ & $0.5 \mathrm{~V}$ \\
\hline PP3 & 0.1 & 0.1 or $0.025 \mathrm{~A}$ & $2 \mathrm{~V}$ \\
\hline
\end{tabular}

A processor was first used for one single element tested and for a single type of case.

To minimize electronics clutter, an Arduino Nano was initially used with 2 relays. The first relay is used to charge and the other relay to discharge via a resistor (figure 17).

An LCD display allows you to view the data in real time and the push buttons allow you to launch the test 
(charge, then discharge and finally recharge) to find out the state of health of the element.

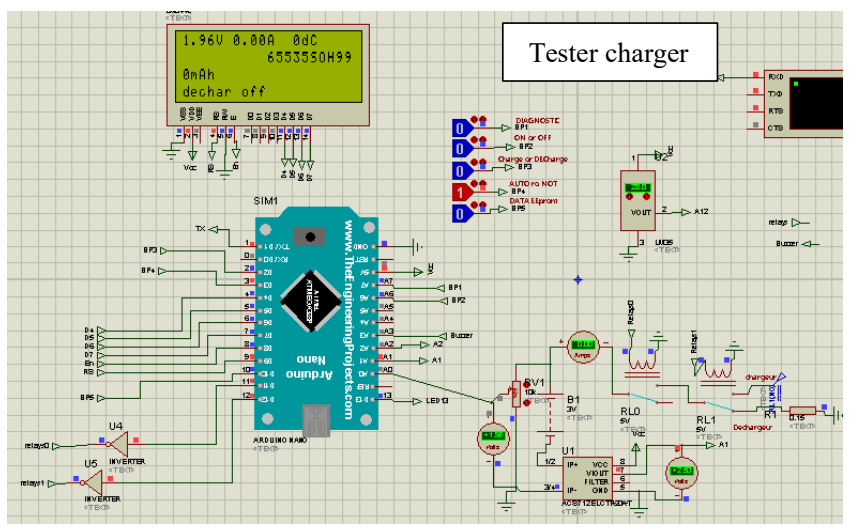

Fig 17. Basic open source NiMH relay tester.

The curves are obtained via the serial link to a PC and an Excel.

An XL4015 switching power supply with voltage adjustment and current limitation using a potentiometer ( $0.1 \mathrm{~A}$ to $5 \mathrm{~A})$ was used to carry out the charge.

An LM35 temperature sensor (placed on the "+" metal part of the charger) and an MLX90614 noncontact sensor via the $\mathrm{I} 2 \mathrm{C}$ were tested.

The ACS712 current sensor is chosen to minimize the losses compared to a shunt resistance and makes it possible to measure the charge and discharge current. An interrupt routine is used to take measurements every $1 \mathrm{~s}$. The internal resistance measurement is carried out every 2 minutes, as well as the sending of data to the PC.

Schematic can be improved as follow (cf. figure 18): relays can be replaced by transistors to increase the reliability of the charger/tester.
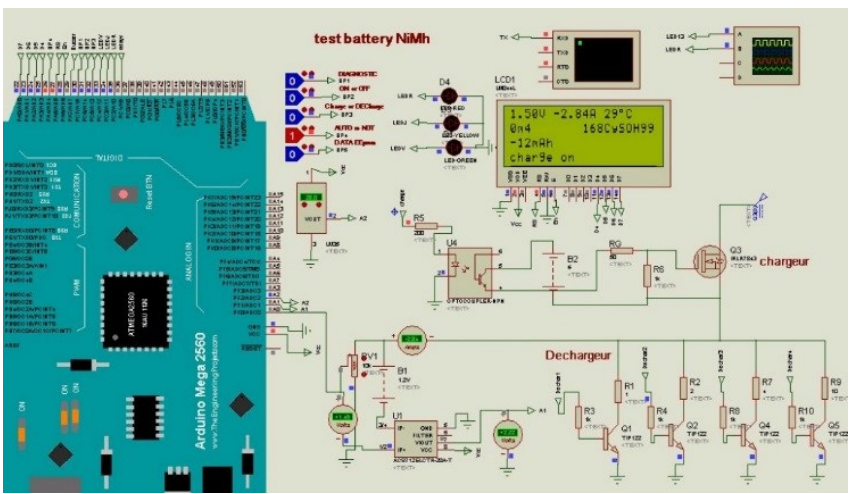

Fig 18. Resistor Switching Constant Current Discharge NiMH improved tester
To have a constant discharge current, several resistors can be switched. This is a simple solution, but it uses a lot of Arduino processor outputs.

It is also possible to perform a constant current discharge using a chopper using a PWM output as in the following electrical diagram (figure 19).

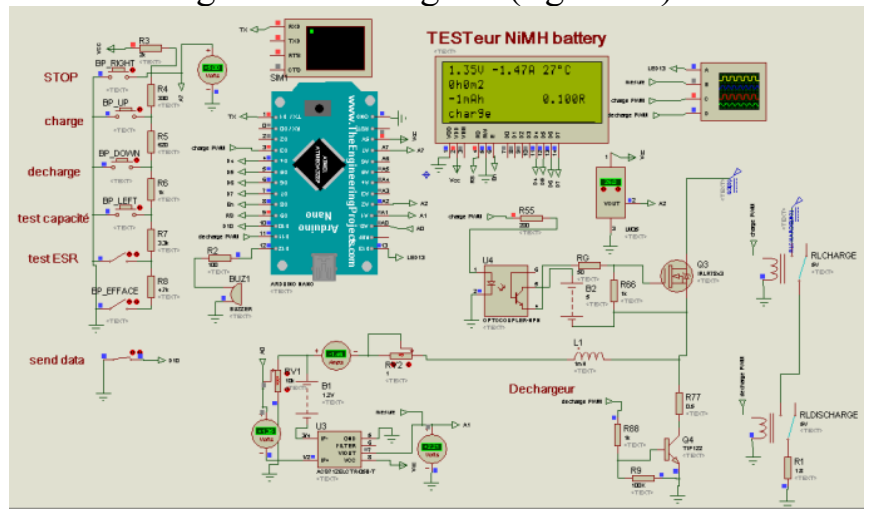

Fig 19. PWM Constant Current Discharge or charge NiMH Transistor Tester.

Notes:

- The regulation of the charge current by an independent external power supply using LM2596, can be replaced by the Arduino itself but the set-point current must be managed by the user.

- To no longer go through a PC to visualize the curves of the voltage evolution, an ESP32 Oled 128x64 $(2.5 \mathrm{~cm} * 1.25 \mathrm{~cm})$ processor from HELTEC, TTGO, M5Stack can be implemented.

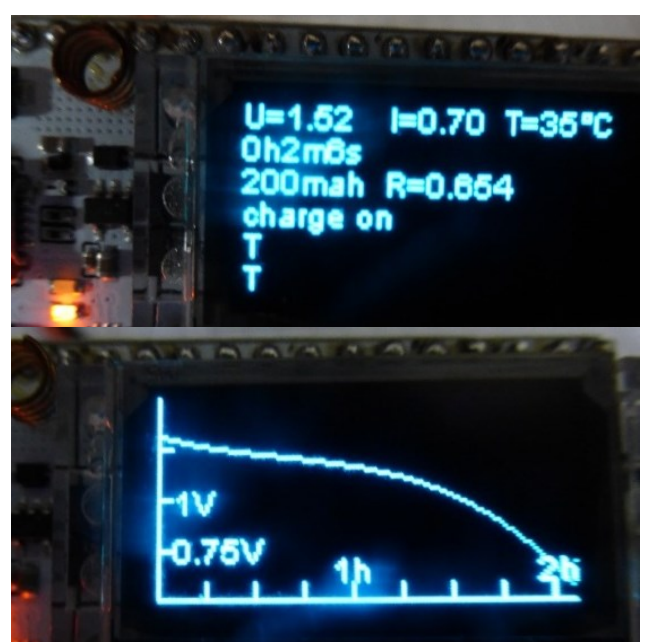

Fig 1. Tester NiMH with OLED ESP 32

When the charger and the tester are made, it is possible to make a cycler to check the lifespan and the possible number of cycles of household NiMH cells, but this monopolizes the electronics for several months. Indeed, for AA elements only 5 cycles are possible in a day. It therefore takes 200 days to reach 1000 cycles corresponding to an average lifespan. 


\section{Aging, failure replacement of NiMH}

The lifetime of NiMH cells will depend on the DOD (depth of discharge) and temperature [16].

The DOD is given by the following relation with SOC (state of charge) and Q capacity.

$$
D O D=\frac{\operatorname{SOC}(A . h)}{Q_{\text {nominal }}(A . h)}
$$

Some literatures use the following equation (7) to model the number of life cycles from testing:

$$
\text { Lyfe }(S O C)=\text { Cycle }_{\max } \cdot\left(\frac{Q_{\text {nominal }}}{S O C}\right)^{U_{0}} \cdot e^{U_{1} \cdot \frac{S O C}{Q_{\text {nominal }}}}
$$

Example of cyclers tests:

Three cyclers that test the elements:

- a cycle cycler with a $100 \%$ DOD,

- another cycler at $50 \%$

- and another at $25 \%$.

The max cycle coefficients, $U_{0}, U_{1}$ are determined to have the curve of figure 21 . The cycling is stopped for a loss of $20 \%$ of the energy capacity or by an increase in ESR of the value 3 times greater than face value.

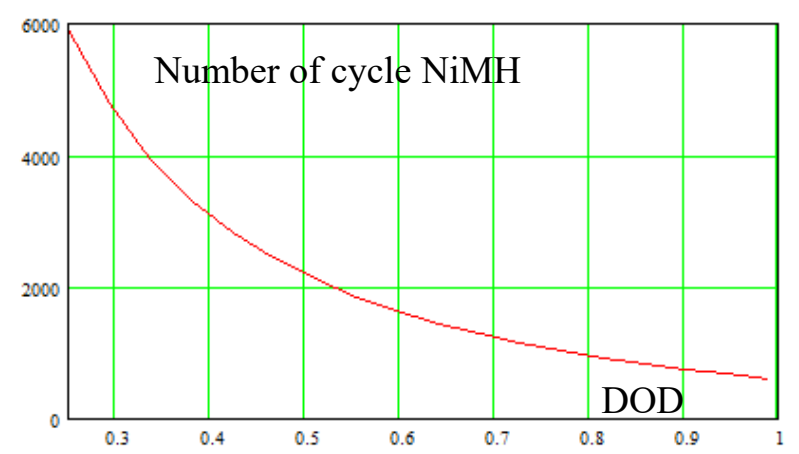

Fig 20. Number of cycles vs DOD, NiMH $25^{\circ} \mathrm{C}$

Obsolescence also depends on temperature and discharge and charge currents.

There are four main reasons for NiMH battery failures:

1) Internal short-circuit ("punching" of the separator).

2) Open circuit (electrode breakage due to expansion and distortion between charge and discharge).

3) Increased self-discharge (reduced system operation).

4) Increase in impedance and decrease in capacity (drying out of the electrolytic, degradation of the electrodes, etc.).
Cases 1) and 2) are synonymous of a failure without any possible compromise.

The case 3) will require more frequent recharges, which will be inconvenience for the user. But, selfdischarge tests require a minimum of one week of measurement and will therefore be difficult to use.

The case 4) is not totally fatal: battery can always operate in a "degraded mode" but only for a system requiring small current.

In this last case, our charger/tester warns the users when the impedance reaches 3 times the nominal internal resistance value (cf. Table 1). Thus, the battery will be rejected by our charger's control algorithm.

Finally, we can mention that in the near future, household NiMH batteries could be replaced by Liion cells, which are recharged via a universal USB charger for electronics.

The price of such Li-ion pocket box elements is low as can be seen in the table 2, depending on the energy capacity.

Tableau 2 : Small Li-ion Punch Rechargeable Cell

\begin{tabular}{|c|c|c|c|c|c|}
\hline $\begin{array}{c}\text { capacity } \\
(\text { A.h })\end{array}$ & $\begin{array}{c}\text { Weight } \\
(\mathrm{g})\end{array}$ & $\begin{array}{c}\text { Size } \\
(\mathrm{mm})\end{array}$ & $\begin{array}{c}\text { Price } \\
(€)\end{array}$ & $\begin{array}{c}\text { volume } \\
\left(\mathrm{mm}^{3}\right)\end{array}$ & $\begin{array}{c}\text { ESR } \\
(\mathrm{m} \Omega)\end{array}$ \\
\hline 0,1 & 5 & $22 * 15 * 6,8$ & 1,63 & 2244 & \\
\hline 0,2 & 7 & $27 * 20 * 8,5$ & 1,65 & 4590 & \\
\hline 0,3 & 10 & $34 * 20 * 8,5$ & 1,68 & 5780 & \\
\hline 0,8 & 18 & $42 * 25 * 9$ & 2,25 & 9450 & 190 \\
\hline 1,5 & 30 & $54 * 30 * 10$ & 3 & 16200 & \\
\hline 1,8 & 32 & $54 * 34 * 10$ & 5,1 & 18360 & \\
\hline 2,3 & 42 & $18 * 18 * 65$ & 3 & 210600 & 80 \\
\hline
\end{tabular}

What are lithium batteries worth with domestic cases?

We performed several capacity and ESR measurements on $2 \mathrm{Li}$-ion cases. Results are reported in table 3.

Table 3: Lithium battery domestic characteristics

\begin{tabular}{|l|l|l|l|l|l|}
\hline Case & $I_{\text {charge }}$ & $\begin{array}{l}I_{\text {discharg }} \\
\max \end{array}$ & $\begin{array}{l}\text { ESR } \\
\Omega\end{array}$ & $\begin{array}{l}\text { Capacity } \\
\text { (mA.h) }\end{array}$ & $\begin{array}{l}\text { Capacity } \\
\text { (mA.h) }\end{array}$ \\
\hline AA & $0.5 \mathrm{~A}$ & $2 \mathrm{~A}$ & 0.33 & $\begin{array}{l}715 \mathrm{~mA} . \mathrm{h} \\
\text { at 1.7A }\end{array}$ & $\begin{array}{l}1400 \\
\text { at 0.02A }\end{array}$ \\
\hline PP3 & 0.3 & $1 \mathrm{~A}$ & 0.57 & $\begin{array}{l}460 \mathrm{~mA} . \mathrm{h} \\
\text { at 1A }\end{array}$ & $\begin{array}{l}960 \\
\text { at 0.02A }\end{array}$ \\
\hline
\end{tabular}

We notice that behaviour of Li-ion is similar to the one of NiMH. (loss of capacity vs current and ESR). Moreover, for the AA case, we observed that the case temperature increment for a constant discharge 
current of $1.7 \mathrm{~A}$ is $40^{\circ} \mathrm{C}$ which is relatively large and may increase the obsolescence of the lithium battery.

\section{Conclusion}

It takes a relatively long time to test the proper functioning of domestic NiMH $2300 \mathrm{~mA}$.h cells because they have to be discharged to values below 1C. A good test compromise is to discharge at $0.5 \mathrm{C}$ : it allows a full classical test cycle) in 6 hours (charge $2 \mathrm{~h}, 100 \%$ discharge $2 \mathrm{~h}$ and recharge $2 \mathrm{~h}$ ).

However, this article shows that a correct estimate of the state of health requires discharging only at $25 \%$ of the energy capacity which reduces the test duration down to roughly 1.75 hour (quick charge $1 \mathrm{~h}, 25 \%$ discharge $0.5 \mathrm{~h}$ and quick recharge $0.25 \mathrm{~h}$ ).

This article demonstrates that it is possible to realize a low cost digital charger with several modes (expert, candid) able to control charge using a contactless or contactless temperature measurement and able to determine the state of health of the battery with simple algorithms.

Finally, we hope that chargers indicating the state of health will make possible to democratize rechargeable batteries for domestics uses.

\section{References:}

[1] David Holburn web site 2021 :

http://www2.eng.cam.ac.uk/ dmh/ptialcd/battery/in dex.htm

[2] Eurostat recycling of batteries and accumulators 2018 web site:

https://ec.europa.eu/eurostat/statisticsexplained/index.php?title=Waste_statistics recycling of batteries and accumulators

[3] wiki : Electric_battery https://en.wikipedia.org/wiki/Electric battery [4] M. A. Parvez Mahmud, N.Huda, , Shahjadi Hisan Farjana « Comparative Life Cycle Environmental Impact Analysis of Lithium-Ion (LiIo) and Nickel-Metal Hydride (NiMH)

Batteries » MDPI journals 2019

https://www.mdpi.com/2313-0105/5/1/22/htm

[5] Piles jetables ou rechargeables, Quelles piles acheter ? magazine "UFC que choisir"

https://www.quechoisir.org/guide-d-achat-pilesrechargeables-n10337/\#jetables-ou-rechargeables [6] «Guide, Réduisez votre budget piles » 60millions-mag https://www.60millionsmag.com/2012/09/05/reduisez-votre-budget-piles$\underline{8064}$
[7] Datasheet NiMH AA

https://eneloop101.com/wp-

content/uploads/2017/02/HR-3UTGB.pdf

https://data.energizer.com/pdfs/hr6-2650_eu.pdf

https://datasheet.octopart.com/5030852-Ansmann-

datasheet-5400527.pdf

https://data.energizer.com/pdfs/nickelmetalhydride appman.pdf

https://www.econologie.com/fichiers/partager2/128 9845967x01YXD.pdf

https://www.econologie.com/fichiers/partager2/128

98454214KbMUe.pdf

https://batteryuniversity.com/learn/article/how to

measure internal_resistance

[8]E. Kuhn, C. Forgez, G. Friedrich Modèle pour accumulateurs $\mathrm{Ni}-\mathrm{mH}$ en vue d'une application pour véhicule hybride électrique, int conf EPF'2002 France

[9] Mathworks web site: electric model NiMH

https://fr.mathworks.com/help/physmod/sps/powers ys/ref/battery.html

[10] Farnell web site: Datasheet PP3 9V NiMh

http://www.farnell.com/datasheets/39693.pdf

[11] Blogs "test domestic battery"

https://www.powerstream.com/AA-tests.htm

https://www.philohome.com/batteries/bat.htm

https://www.geckoandfly.com/10056/rechargable-

aa-and-aaa-nimh-batteries-comparison/

[12] Blog "test charger NiMh"

https://lygte-

info.dk/info/batteryChargingNiMH\%20UK.html

http://bricolsec.canalblog.com/archives/2012/11/02/ 25480956.html

[13] Arduino forum

BMS, State of charge and estimate health battery

lithium with Arduino

BMS, Etat de charge et santé de batterie lithium, banc cyclage (arduino)

[14] Analog device web site: Charger LTC4010

https://www.analog.com/en/products/ltc4010.html

RScomposant web site: https://fr.rsonline.com/web/p/controleurs-de-charge-de-

batterie/7619531/

[15] Sivert, F. Betin, B.Vacossin, H. Caron "État de Santé de batterie lithium par Régression Linéaire et par Incremental Capacity Analyst" SGE 2020 july 2021 Nantes

[16] S. Drouilhet, B.L. Johnson, A Battery Life Prediction Method for Hybrid Power Applications https://www.nrel.gov/docs/legosti/fy97/21978.pdf

[17] Stephane Blanchin Batteries nickel-métalhydrure (Ni-MH) - Technologie, applications et enjeux BE 8 621, Techniques de l'ingénieur 2019

\section{Creative Commons Attribution License 4.0 (Attribution 4.0 International, CC BY 4.0)}

This article is published under the terms of the Creative Commons Attribution License 4.0

https://creativecommons.org/licenses/by/4.0/deed.en_US 